\title{
Knowledge and Confidence of Clinicians in an Irish CAMHS Service when Working with Transgender Youth; and the Factors Clinicians Report will Assist them in this Work. - Erratum
}

Sinéad Hodgins, Triona Byrne, Marelise Spies and Kevin Madigan

https:/ / doi.org/10.1017/ipm.2020.24, Published by Cambridge University Press, 29 June 2020

When originally published, this article's introduction was erroneously moved to the end of the paper. This has now been corrected in the original article.

The Publisher apologises for this oversight.

Reference

Hodgins, S., Byrne, T., Spies, M., \& Madigan, K. (2020). Knowledge and confidence of clinicians in Irish CAMHS when working with transgender youth; and the factors clinicians report will assist them in this work. Irish Journal of Psychological Medicine, 1-10. doi: 10.1017/ipm.2020.24 